\title{
Inertia gravity waves in the upper troposphere during the MaCWAVE winter campaign - Part I: Observations with collocated radars
}

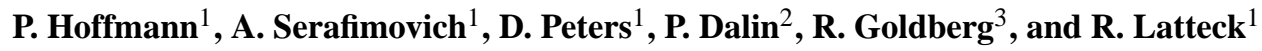 \\ ${ }^{1}$ Leibniz-Institut für Atmosphärenphysik, Kühlungsborn, Germany \\ ${ }^{2}$ Swedish Institute of Space Physics, Kiruna, Sweden \\ ${ }^{3}$ NASA/Goddard Space Flight Center, Greenbelt, Maryland, USA
}

Received: 6 March 2006 - Revised: 16 September 2006 - Accepted: 18 October 2006 - Published: 21 November 2006

\begin{abstract}
During the MaCWAVE campaign, combined rocket, radiosonde and ground-based measurements have been performed at the Norwegian Andøya Rocket Range (ARR) near Andenes and the Swedish Rocket Range (ESRANGE) near Kiruna in January 2003 to study gravity waves in the vicinity of the Scandinavian mountain ridge. The investigations presented here are mainly based on the evaluation of continuous radar measurements with the ALWIN VHF radar in the upper troposphere/ lower stratosphere at Andenes $\left(69.3^{\circ} \mathrm{N}, 16.0^{\circ} \mathrm{E}\right)$ and the ESRAD VHF radar near Kiruna $\left(67.9^{\circ} \mathrm{N}, 21.9^{\circ} \mathrm{E}\right)$. Both radars are separated by about $260 \mathrm{~km}$. Based on wavelet transformations of both data sets, the strongest activity of inertia gravity waves in the upper troposphere has been detected during the first period from 2426 January 2003 with dominant vertical wavelengths of about $4-5 \mathrm{~km}$ as well as with dominant observed periods of about 13-14 $\mathrm{h}$ for the altitude range between 5 and $8 \mathrm{~km}$ under the additional influence of mountain waves. The results show the appearance of dominating inertia gravity waves with characteristic horizontal wavelengths of $\sim 200 \mathrm{~km}$ moving in the opposite direction than the mean background wind. The results show the appearance of dominating inertia gravity waves with intrinsic periods in the order of $\sim 5 \mathrm{~h}$ and with horizontal wavelengths of $200 \mathrm{~km}$, moving in the opposite direction than the mean background wind. From the derived downward energy propagation it is supposed, that these waves are likely generated by a jet streak in the upper troposphere. The parameters of the jet-induced gravity waves have been estimated at both sites separately. The identified gravity waves are coherent at both locations and show higher amplitudes on the east-side of the Scandinavian mountain ridge, as expected by the influence of mountains.
\end{abstract}

Correspondence to: P. Hoffmann

(hoffmann@iap-kborn.de)
Keywords. Meteorology and atmospheric dynamics (Mesoscale meteorology; Middle atmosphere dynamics; Waves and tides)

\section{Introduction}

To understand the structure and dynamics of the atmosphere and its variability, it is important to know the coupling processes between different atmospheric regions from the troposphere up to the thermosphere. The dynamical coupling mainly includes the generation of different atmospheric waves (gravity waves, tides, planetary waves), their propagation through the atmosphere, the interaction between different waves and their impact upon the mean circulation. Today it is recognized that gravity waves are an essential part of the dynamics of the upper atmosphere. The theory to describe these waves has been essentially stimulated by the pioneering work of Hines (1960). Over the last decades, a multitude of experimental observations, theoretical and modelling studies have considerably improved our understanding of gravity waves and their role in the atmospheric circulation (e.g., Fritts, 1984, 1989; Fritts and Alexander, 2003).

To study the dynamical coupling processes, a highly coordinated rocket and ground-based program MaCWAVE (Mountain and Convective Waves Ascending VErtically) was performed at the Norwegian Andøya Rocket Range (ARR) near Andenes $\left(69.3^{\circ} \mathrm{N}, 16^{\circ} \mathrm{E}\right)$ and the Swedish Rocket Range (ESRANGE) near Kiruna $67.9^{\circ} \mathrm{N}, 21.1^{\circ} \mathrm{E}$ ), at first during summer conditions in July 2002 and continued with a winter campaign in January 2003. The campaigns were designed to investigate gravity waves linked to the Scandinavian mountain ridge, to track these waves using different instruments such as radar/rocket/lidar/radiosondes

Published by Copernicus GmbH on behalf of the European Geosciences Union. 
Table 1. Parameters of the VHF radar (ALWIN) at Andenes and the Esrange MST radar (ESRAD) at Kiruna.

\begin{tabular}{lll}
\hline & ALWIN VHF Radar & Esrange MST Radar \\
\hline Geographical location & $69.3^{\circ} \mathrm{N}, 16.0^{\circ} \mathrm{E}$ & $67.9^{\circ} \mathrm{N}, 21.9^{\circ} \mathrm{E}$ \\
Operating frequency & $53.5 \mathrm{MHz}$ & $52.5 \mathrm{MHz}$ \\
Peak power/duty cycle & $36 \mathrm{~kW} / 5 \%$ & $72 \mathrm{~kW} / 10 \%$ \\
Transmitting antenna & $144 \mathrm{Yagi}$ array & $144 \mathrm{Yagi}$ array \\
Antenna aperture (area) & $1900 \mathrm{~m}^{2}$ & $2025 \mathrm{~m}^{2}$ \\
Half-power beam width & $6^{\circ}$ & $5^{\circ}$ \\
Pulse length & $4 \mu \mathrm{s}$ & $4 \mu \mathrm{s}$ \\
N of transmitter/receiver & 6 & 6 \\
Code & Single pulse & Single pulse \\
Coherent integration & 256 & 256 \\
Vertical resolution & $300 \mathrm{~m}$ & $300 \mathrm{~m}$ \\
Altitude range & $2-16 \mathrm{~km}$ & $2-16 \mathrm{~km}$ \\
Time resolution & $\sim 2 \mathrm{~min}$ & $\sim 2 \mathrm{~min}$ \\
Methods & DBS, SA(FCA) & SA(FCA) \\
\hline
\end{tabular}

data from troposphere up to the mesosphere, and to detect energy dissipation in the upper atmosphere produced by wave breaking. For more details on both campaigns we refer the reader to Goldberg et al. $(2004,2006)$. During the first MaCWAVE summer campaign, investigations of gravity waves in the troposphere and stratosphere have been carried out using combined radar and lidar data (Schöch et al., 2004).

Here we report on measurements of upper tropospheric and lower stratospheric gravity waves at two different locations near the Scandinavian mountain ridge obtained with continuous VHF radar observations during the MaCWAVE winter campaign in January 2003. The use of two collocated radars allows us to identify common wave events and to discuss temporal and spatial differences of the observed waves. This a continuative paper to our investigations of the properties of inertia gravity waves in the upper troposphere/lower stratosphere over Northern Germany where the influence of orographically excited waves are weak and an upper tropospheric jet occurred in connection with a poleward Rossby wave breaking event in December 1999 (Peters et al., 2003; Serafimovich et al., 2005).

In this paper we are mainly focussing on the investigation of inertia gravity waves (IGW) induced by a jet streak in the upper troposphere under the presence of strong orographically induced waves. For this purpose the inertia gravity waves at both sides of the Scandinavian mountain ridge have been filtered out from the background winds and mountain waves. In a companion paper (Part II, Serafimovich et al., 2006), comparisons of inertia gravity wave properties diagnosed from observations with the ALWIN radar at Andenes and mesoscale MM5 model data are presented, resulting in a fairly well agreement, and the capabilities of both methods for the analysis of such processes are proved.
The paper is organized as follows. After a short description of the used radars in Sect. 2, the meteorological background for the inertia gravity wave generation is discussed in Sect. 3. Section 4 is devoted to the estimation of inertia gravity wave characteristics for each radar location separately and by a complex cross-spectral analysis of the data of both radars during the period from 24-26 January 2003 with the strongest gravity wave activity. The main results are discussed in Sect. 5 and we give concluding remarks in Sect. 6.

\section{ALOMAR VHF radar (ALWIN) and Esrange MST radar (ESRAD)}

The investigations presented here are based on observations mainly made by collocated radars at high latitudes in the vicinity of the Scandinavian mountain ridge. We processed data from the ALOMAR VHF radar (ALWIN) in Andenes and Esrange MST radar (ESRAD) in Kiruna. Details of the radar parameters used are summarized in Table 1. Both radars, the ALWIN radar in Andenes and ESRAD radar in Kiruna are separated by about $260 \mathrm{~km}$ and have comparable characteristics. They are using the same antenna size and nearly the same operation frequency 53.5 and $52.0 \mathrm{MHz}$.

The ESRAD radar (Chilson et al., 1999) as well as the ALWIN radar (Latteck et al., 1999) are measuring wind components in the Stratospheric-Tropospheric (ST) mode at the height range of 2-16 km with a resolution in height of $300 \mathrm{~m}$ and in time of $2 \mathrm{~min}$. The transmitter and the data acquisition system were built by ATRAD (Atmospheric Radar Systems Pty. Ltd, Thebarton, S.A., Australia). Wind measurements are carried out in the Spaced Antenna (SA) mode using the Full Correlation Analysis (FCA) method and additionally 
for the ALWIN radar by the Doppler-Beam-Swinging (DBS) method. For further investigations in this work the data averaging over $30 \mathrm{~min}$ intervals is sufficient to estimate parameter of inertia gravity waves. In order to avoid missing values in the time series caused by low signal-to-noise ratios of the backscattered radar signals, only height channels up to about $14 \mathrm{~km}$ have been evaluated.

\section{Meteorological background}

The MaCWAVE winter campaign were performed at Andenes and Kiruna at two periods from 24-26 January and from 28-29 January 2003 (Goldberg et al., 2006). Figure 1 shows the zonal winds derived from ECMWF (European Center for Medium-Range Weather Forecast) analysis for the $500 \mathrm{hPa}$ level corresponding to a height of about $6 \mathrm{~km}$ for both periods. On 24 January 2003 during the first part of the campaign (Fig. 1, upper panel), an north-eastward directed jet stream occurs across the Scandinavian mountains with a centre south of the Andøya-Esrange region in Northern Scandinavia. During the second part of the MaCWAVE winter campaign from 28-29 January 2003 (Fig. 1, lower panel) the centre of the jet stream is placed over Central Europe and the horizontal winds over Northern Scandinavia turned to weaker northwesterlies.

To set these meteorological situations in relation to the mean winter behaviour, Fig. 2 represents the ECMWF zonal winds at $\left(69^{\circ} \mathrm{N}, 16^{\circ} \mathrm{E}\right)$ near Andenes during both periods of the MacWAVE winter campaign on 24-26 January and 2829 January 2003, respectively, in comparison to the climatologically zonal winds of the mean winter months December, January and February from 1991-2001. The zonal wind shows two significant peaks at about 9 and $30 \mathrm{~km}$ during the first period (Fig. 2, left part). On 28-29 January during the second part of the winter campaign (Fig. 2, right part), the tropospheric jet in the zonal wind disappeared.

In Fig. 3 the mean winds derived for both radar locations on the east and west side of the Scandinavian mountain ridge are presented. The temporal development of the zonal wind (Fig. 3a) is characterized by an oscillation with a period of about 1-2 days with maxima $\left(\sim 40 \mathrm{~ms}^{-1}\right)$ of the zonal wind on 24 January at both locations, whereas the maxima in the meridional wind $\left(\sim 30 \mathrm{~ms}^{-1}\right)$ (Fig. 3b) occur approximately $12 \mathrm{~h}$ later. Note that the zonal winds are larger at Kiruna by $\sim 10 \mathrm{~ms}^{-1}$ (Figs. 3c and d) as expected due to the amplification by mountain waves (Queney, 1948; Smith, 1979). However, further investigations are required to understand these processes in more detail. During the second part of the winter MaCWAVE campaign on 28-29 January 2003, the wind variations occur markedly weaker at both radar locations in comparison to the period from 24-26 January 2003, consistent with the ECMWF results shown in Fig. 1.

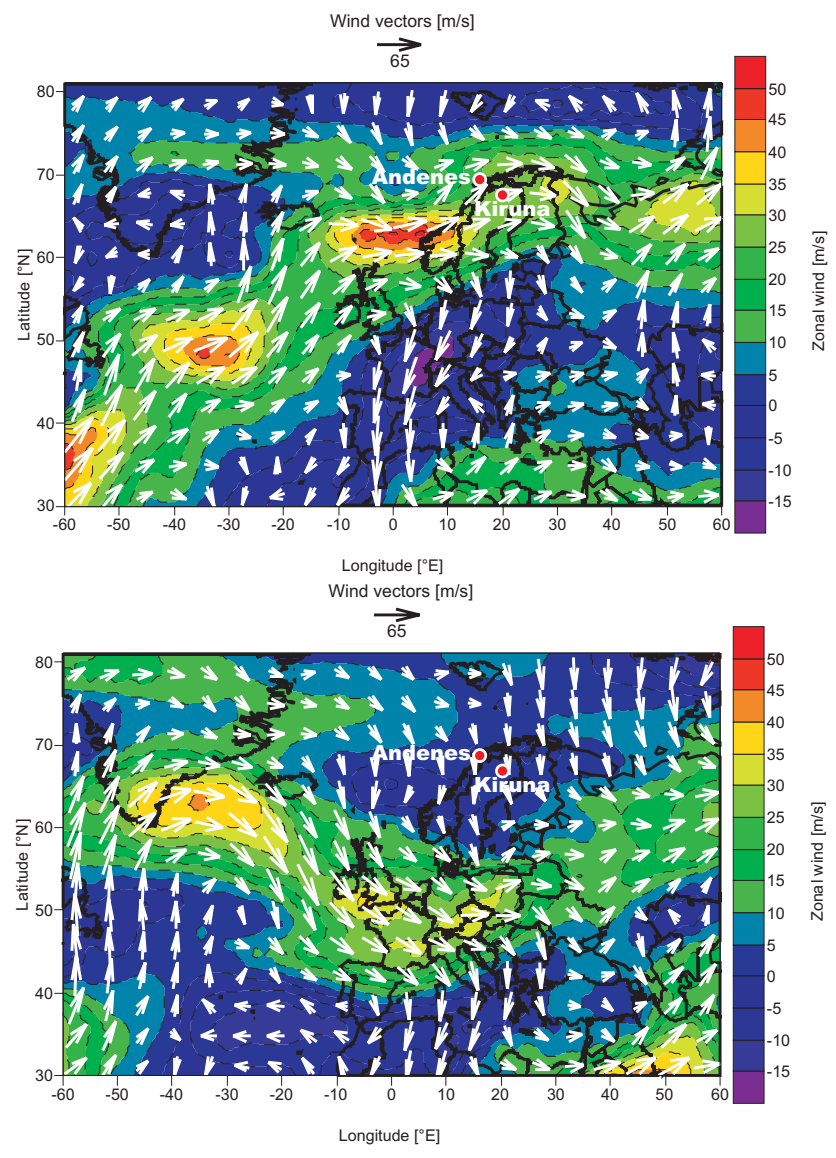

Fig. 1. Zonal wind and wind vectors derived from ECMWF analysis for the $500 \mathrm{hPa}$ level at 24 January 2003, 12:00 UT (upper panel) and 28 January 2003, 12:00 UT (lower panel).

\section{Data analyses}

\subsection{Detection of gravity waves}

The calculation of gravity wave parameters is based on wind perturbations, which have been estimated from the wind measurements after linear interpolations to substitute missing values following by an appropriate broad band-pass filtering in height and time to remove the background winds. Suppose, that the perturbations are described by variations of amplitudes $a(x, y, z, t)$ of the wind components

$a(x, y, z, t)=a_{0} \cdot \exp \left(i\left(k x+l y+m z-\omega_{o b} t\right)\right)$,

where $a$ can be perturbations of zonal $u^{\prime}$ or meridional $v^{\prime}$ winds, temperature $T^{\prime}$ or pressure $p^{\prime}$ with a time $t$. The zonal, meridional and vertical wave numbers are denoted by $k, l$ and $m$ in x-, y-, z-directions, respectively, and $\omega_{o b}$ is the wave frequency observed at a fixed location. With the Doppler relation

$\omega_{o b}=\hat{\omega}+\bar{u} k_{h}$, 

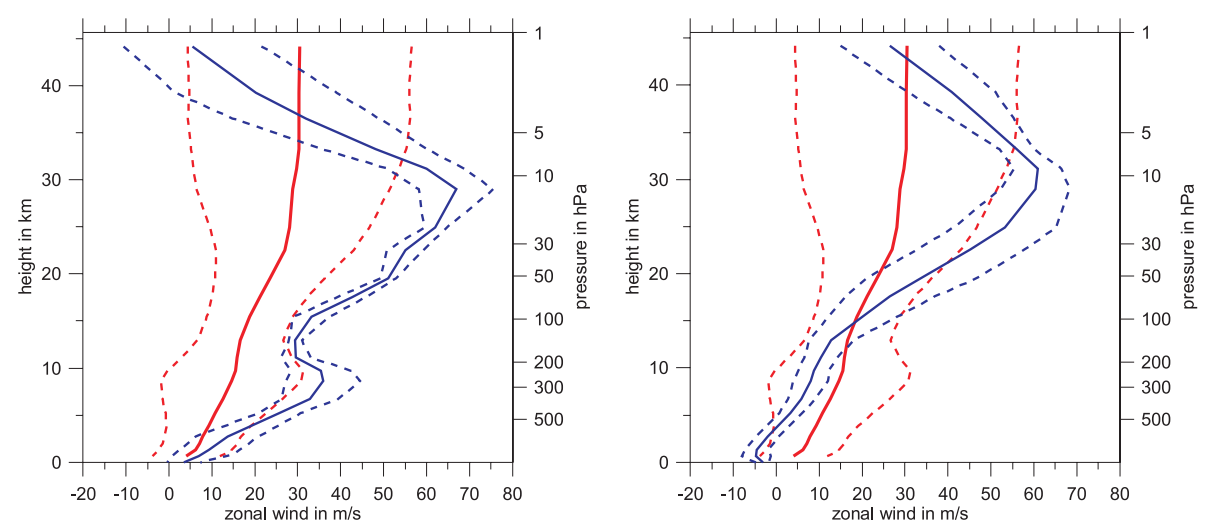

Fig. 2. Mean climatologic zonal winds derived from ECMWF data (red) at $\left(69^{\circ} \mathrm{N}, 16^{\circ} \mathrm{E}\right)$ near Andenes in comparison to the winds during both periods of the MaCWAVE winter campaign (blue) on 24-26 January 2003 (left) and 28-29 January 2003 (right). The variances are represented by the dashed lines.
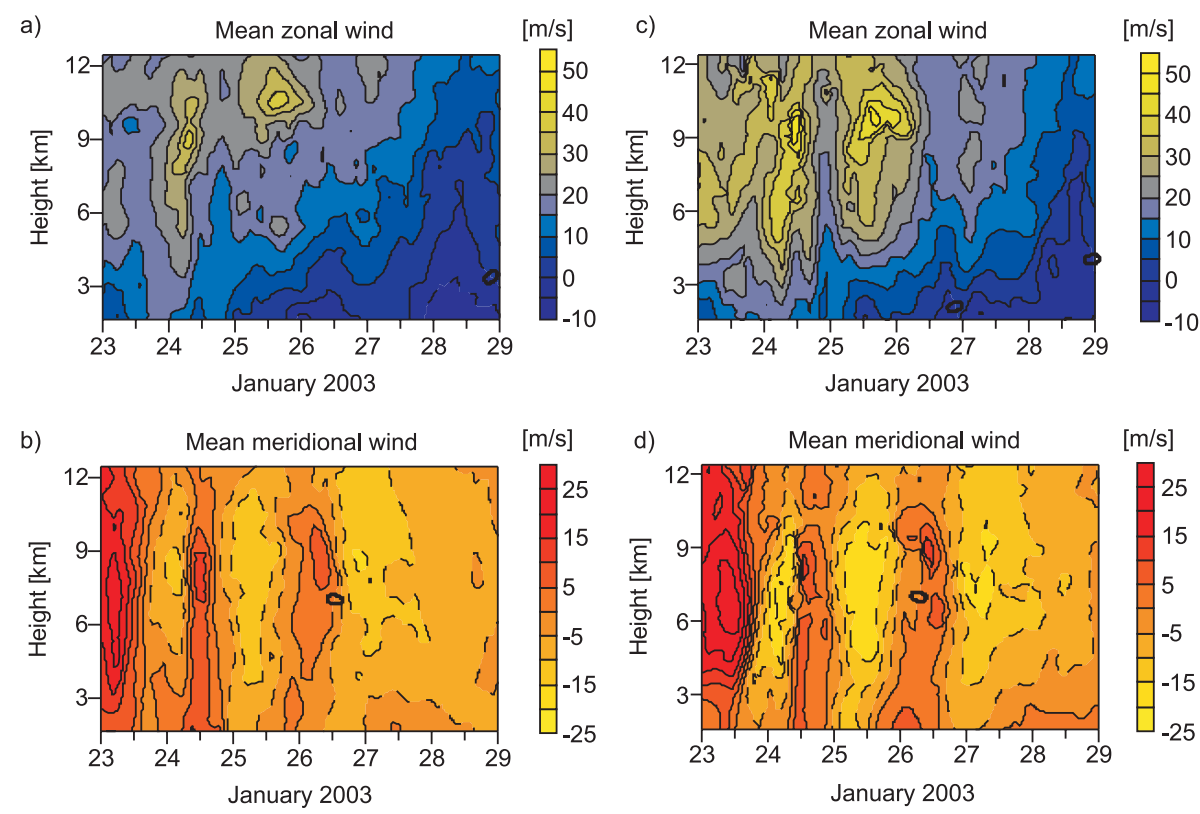

Fig. 3. Mean zonal and meridional winds measured at Andenes (a, b) and Kiruna (c, d) from 23-29 January 2003. The data are smoothed using a low-pass filter with cut-off frequencies corresponding to $4 \mathrm{~h}$ in time and $600 \mathrm{~m}$ in altitude.

$\omega_{o b}$ depends on the intrinsic frequency $\hat{\omega}$, the horizontal wave number $k_{h}=\sqrt{k^{2}+l^{2}}$ and the mean background horizontal wind component $\bar{u}$ given in the same direction as the horizontal wave number $k_{h}$. Corresponding to Zink and Vincent (2001), we adopt here the convention of a positive intrinsic frequency $\hat{\omega}$ and define a negative vertical wave number $m$ for waves propagating energy upwards.

The perturbations are characterized by a superposition of atmospheric waves with different frequencies. In order to estimate inertia gravity wave parameters, individual waves have to be separated or isolated by the application of reasonable band-pass filtering methods. To detect the presence of a wave in the data and to avoid arbitrary choices of inappro- priate filter parameters, a wavelet transform has been applied (Torrence and Compo, 1998; Zink and Vincent, 2001). This technique is becoming a common tool for analysing localized variations due to their possibilities to resolve the waves in frequency domain as well as in the time or height. Details of the methods used here are presented in Serafimovich et al. (2005).

In order to examine the height-time distribution of the wind perturbations over the whole period of the MaCWAVE winter campaign, the background winds have been removed with a band-pass filtering with bandwidths of $2-40 \mathrm{~h}$ in time and $0.8-6 \mathrm{~km}$ in height. Then we used the summarized scaled-averaged wavelet power as proposed by Torrence and 

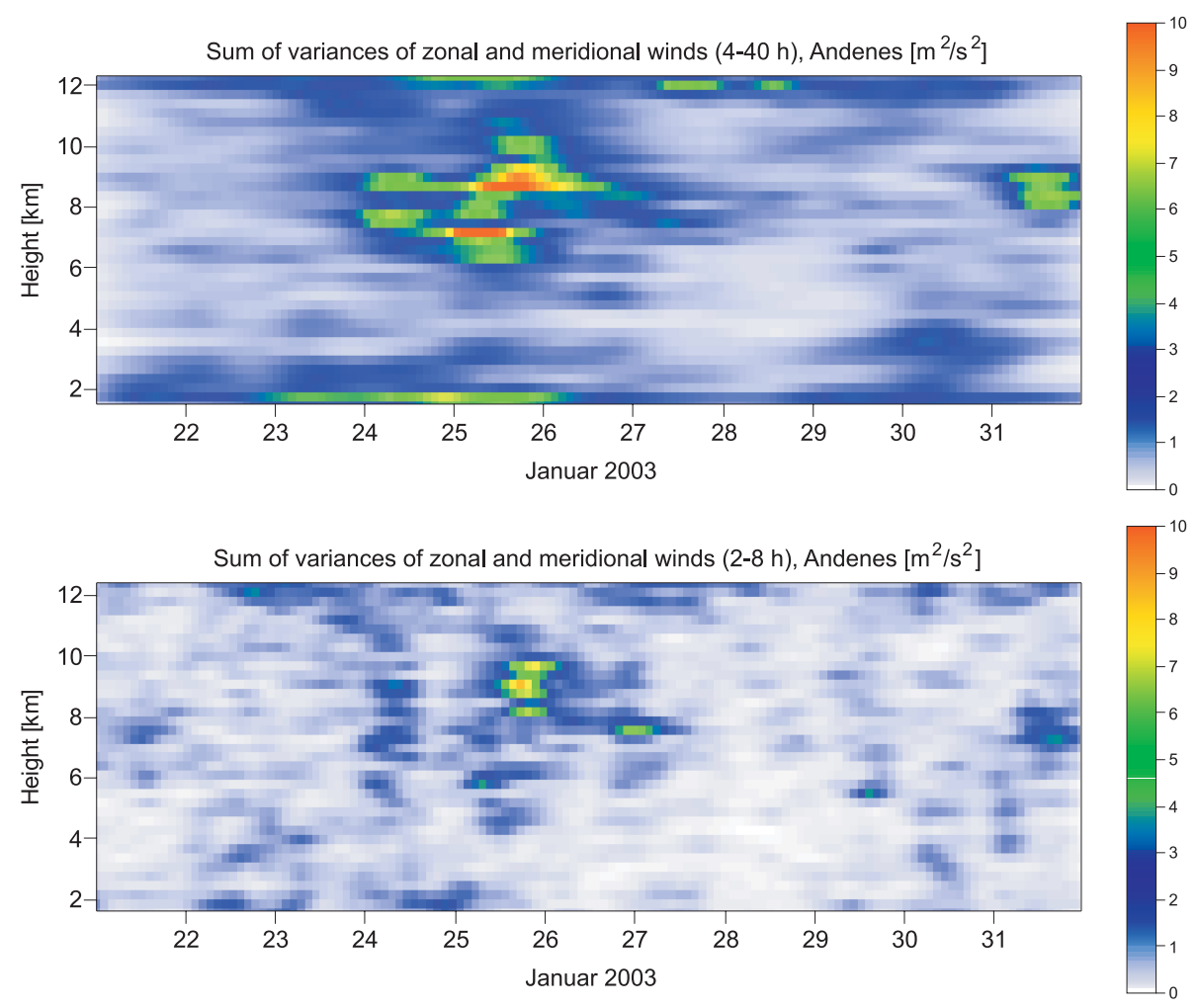

Fig. 4. Sum of variances of zonal and meridional winds for periods $4-40 \mathrm{~h}$ (upper part) and $2-8 \mathrm{~h}$ (lower part), derived from ALWIN VHF radar measurements at Andenes.

Compo (1998). This method is very efficient and comparable to the variances estimated after a classical Butterworth bandpass filtering. Here the variances have been estimated from the zonal and zonal and meridional winds at different heights at Andenes and Kiruna for periods between $4-40 \mathrm{~h}$ and between 2-8 h, respectively (Figs. 4 and 5). For periods between $4-40 \mathrm{~h}$ at Andenes (Fig. 4, upper panel), the strongest values of the summarized variances of zonal and meridional winds occur at heights between $6-10 \mathrm{~km}$ during the first part of the winter MaCWAVE campaign on 24-26 January. The variances for periods between $4-40 \mathrm{~h}$ at Kiruna from 24 26 January (Fig. 5, upper panel) are stronger than the corresponding Andenes values, also at heights above $10 \mathrm{~km}$ as expected due to additional orographic effects. Considering the variances between $2-8 \mathrm{~h}$ with weaker values on $25-26$ January at Andenes (Fig. 4, lower panel) and from 24-26 January at Kiruna (Fig. 5, lower panel) we conclude, that the largest part of the observed variances results from the gravity waves with periods larger than $8 \mathrm{~h}$. During the second part of the campaign from 28-29 January 2003 no strong wave activity has been observed in the upper troposphere at Andenes (Fig. 4) and Kiruna (Fig. 5).

Note that mountain waves generated by a steady background flow are regarded as stationary relative to the ground (Vosper and Worthington, 2002). Therefore the presence of mountain waves cannot be detected with the method used in Figs. 4 and 5. An appropriate method to check the presence of waves in the atmosphere consists in the evaluation of the rotary spectra (Thompson, 1978). The calculation of the rotary spectrum by the Fourier transform of the complex velocity vector $u^{\prime}(z)+i v^{\prime}(z)$ leads to an asymmetrical function. The dominance of clockwise (counterclockwise) rotating waves are associated with negative (positive) frequencies in the rotary power spectrum and allows directly to estimate the vertical direction of energy propagation (Guest et al., 2000). This method has been used by Peters et al. (2003) and Serafimovich et al. (2005) to diagnose an inertia gravity wave generated by a tropospheric jet during a Rossby wave breaking event.

Figure 6 shows the rotary spectra for Andenes and for Kiruna derived from wind perturbations from 1.5-12.4 km only filtered in time for periods between $8-18 \mathrm{~h}$, but here without any filtering in the vertical direction in order to describe the vertical structure. At Andenes (Fig. 6a) the presence of two waves is clearly indicated: one dominating wave with a vertical wavelength of about $\sim 10 \mathrm{~km}$ and a second wave with a vertical wavelength of about $4-5 \mathrm{~km}$. At Kiruna on the lee side of the Scandinavian mountain ridge (Fig. 6b), the amplitudes of a dominating wave with a vertical wavelength of about 7-8 km are larger in comparison to the Andenes results. 

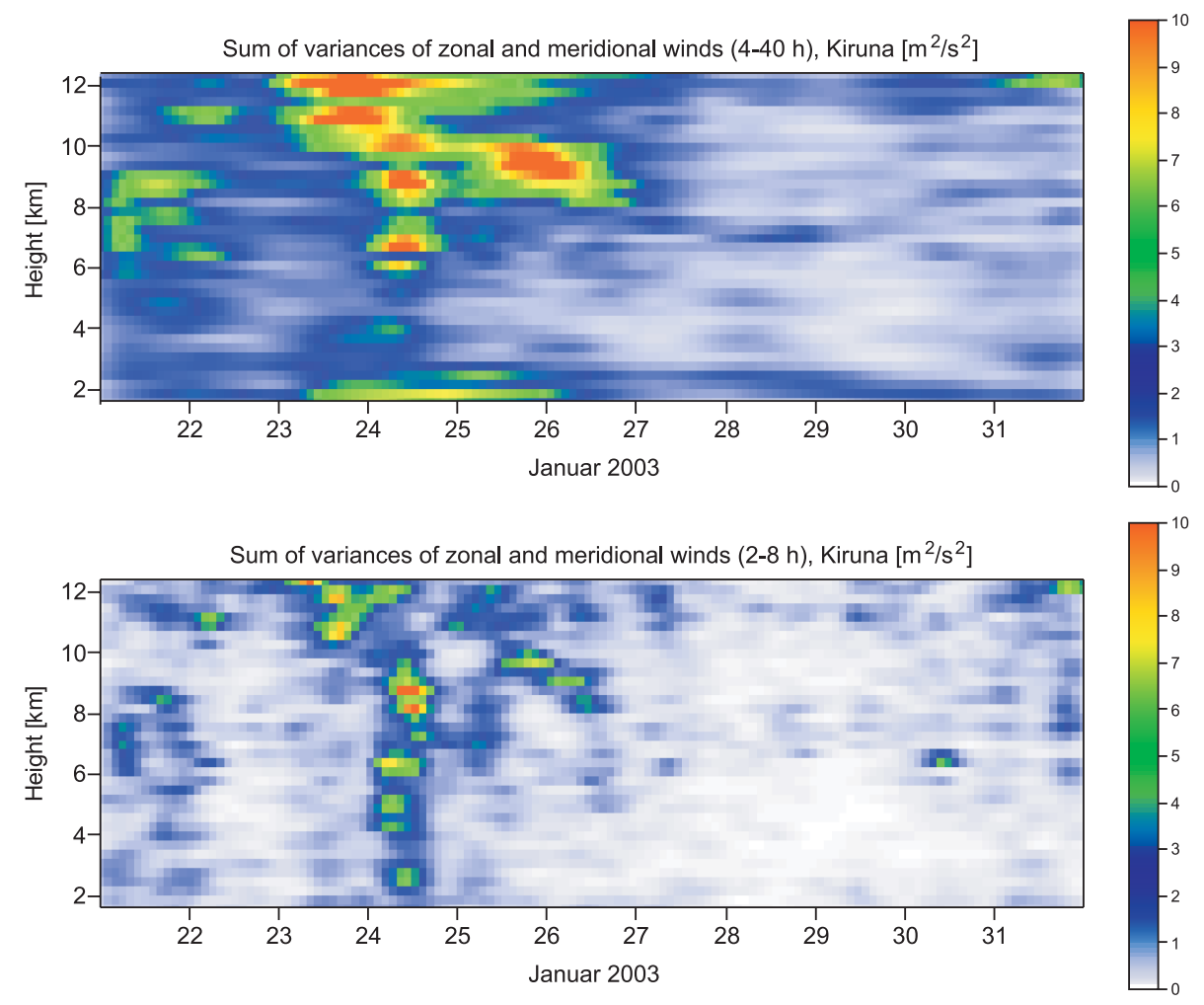

Fig. 5. As Fig. 4, but derived from ESRAD VHF radar measurements at Kiruna.
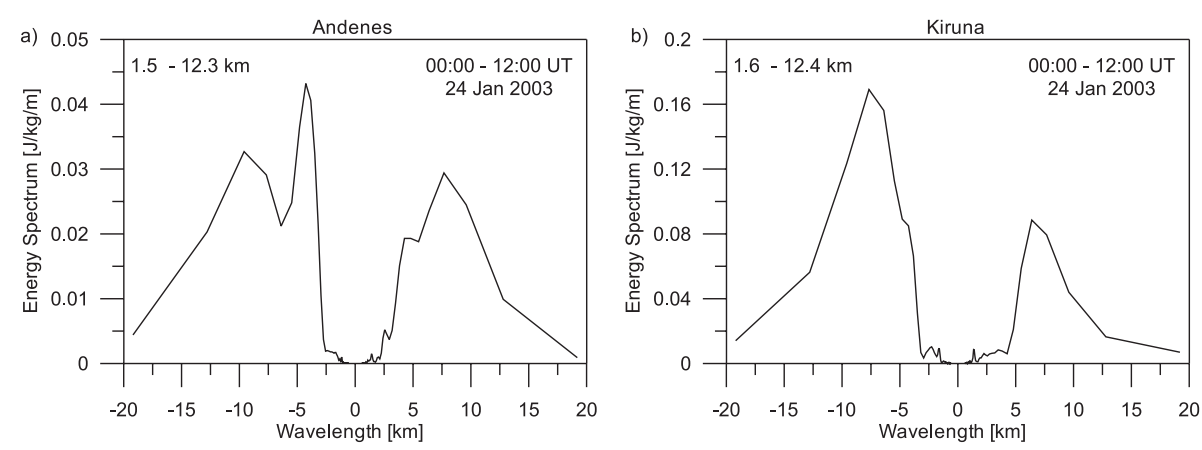

Fig. 6. Results of rotary spectra averaged for $12 \mathrm{~h}$ starting on 24 January 2003, 00:00 UT applied on Radar measurements at Andenes (a) and at Kiruna (b) after band-pass filtering only in the time domain for periods from $8-18 \mathrm{~h}$.

From the dominance of the negative parts of the spectra of the wave with the vertical wavelength of about $10 \mathrm{~km}$ at Andenes and about 7-8 km at Kiruna, we conclude that these waves show upward directed energy propagations. Following Queney (1948) and taking into account, that the mean flow is directed perpendicular to the Scandinavian mountain ridge, we suppose, that these waves represent orographically generated mountain waves. This is also supported by the vertical velocities measured with the ALWIN VHF radar in DBS mode (Fig. 7). The method to use vertical winds measured by VHF radars as indications of mountain waves has been proposed, e.g., by Ecklund et al. (1981), or Balsley and Carter
(1989) and has been compared with models by Vosper and Worthington (2002). As indicated in the mean profile of the vertical winds (Fig. 7, left) and by the horizontal lines in the right part of Fig. 7, we detect a vertical distance of about $5 \mathrm{~km}$ between maxima and minima of the vertical winds on 24-25 January 2003, consistent with the estimated vertical wavelength of $\sim 10 \mathrm{~km}$ derived from the rotary spectra (Fig. 6). Note that the height-time plot of the vertical velocity shows a phase change during 24 and 25 January, in correspondence to the changing mean horizontal winds (Fig. 3). Such a behaviour is characteristic for transient mountain waves as described by Vosper and Worthington (2002). From Figs. 6 and 
7 we conclude that at Andenes an unsteady mountain wave with a vertical wavelength of about $10 \mathrm{~km}$ appeared which has a shorter wavelength on the easterly side of the Scandinavian mountains.

In the following we are focussing on the investigation of the inertia gravity waves with vertical wavelengths of about $5 \mathrm{~km}$ and their relation to the observed jet in the upper troposphere, however under the influence of the mountain waves. To separate and identify these waves and consider their height and time dependence at both radar locations, wavelet transforms have been applied on time series of the zonal and meridional winds for constant height ranges as well as on wind profiles versus height for fixed time intervals. Figure 8 (upper panel) shows the wavelet transform of the time series averaged over the altitude ranges $6-7 \mathrm{~km}$ for Andenes (Fig. 8a) and for Kiruna (Fig. 8c). Enhanced wave activity has been observed on 24-26 January 2003 in the upper troposphere with dominant periods of about $12-14 \mathrm{~h}$, the amplitudes and their significance are higher at Kiruna. Figure 8 (lower panel) represents the wavelet transforms of vertical profiles of horizontal winds averaged over $2 \mathrm{~h}$ during periods with enhanced wave activity for Andenes (Fig. 8b) and for Kiruna (Fig. 8d) showing dominant vertical wavelengths of $\sim 4-5 \mathrm{~km}$, again with larger amplitudes at Kiruna. The significance levels and values influenced by boundary effects are indicated. For details we refer the reader to Torrence and Compo (1998) and Serafimovich et al. (2005).

\subsection{Estimation of gravity wave parameter}

To investigate the characteristics of these gravity waves in detail, we used the information of the wavelet spectra (Fig. 8), and applied a band-pass filtering with bandwidths $8-18 \mathrm{~h}$ and $2-6 \mathrm{~km}$ to estimate and separate wind perturbations from the mean winds.

With the derived zonal and meridional wind perturbations, we use the hodograph technique and the rotary spectra to estimate the parameter of the inertia gravity waves and their relation to the observed jet in the upper troposphere. Both methods have been described in detail by Serafimovich et al. (2005). The rotary spectrum has already been applied on the wind perturbations without any height filtering (Fig. 6) indicating the presence of two waves.

Figure 9 represents the rotary spectra applied on wind perturbations after a band-pass filtering with bandwidths for waves with periods of $8-18 \mathrm{~h}$ and vertical wavelengths between 2 and $6 \mathrm{~km}$. The differences between the positive and negative parts of the spectra are significant by more than $95 \%$ as labeled by the circles, triangles and diamonds. This result clearly indicates the presence of inertia gravity waves with a vertical wavelength of about $5 \mathrm{~km}$ at Andenes and Kiruna. From the dominance of the positive parts of the spectra at both locations, we conclude that these waves show downward directed energy propagations in the troposphere, so that
Table 2. Stokes parameters derived from radar measurements on 25 January 2003 for $1 \mathrm{~h}$ starting from 09:00 UT and averaged in wavelengths from $3.8 \mathrm{~km}$ to $6.4 \mathrm{~km}$.

\begin{tabular}{lcc}
\hline Stokes parameters & Andenes & Kiruna \\
\hline Degree of polarization, $d_{m_{1}, m_{2}}$ & 0.95 & 0.96 \\
Major axis orientation, $\Theta_{m_{1}, m_{2}}$ & $-12^{\circ}$ & $-22^{\circ}$ \\
Phase difference, $\delta_{m_{1}, m_{2}}$ & $-104^{\circ}$ & $125^{\circ}$ \\
Ellipse axial ratio, $R_{m_{1}, m_{2}}$ & 0.54 & 0.42 \\
\hline
\end{tabular}

we assume that these waves are generated by the jet in the upper troposphere.

The hodograph analysis has been introduced by Gill (1982) in connection with a rotating fluid and applied first to IGWs by Cot and Barat (1986). The application of the hodograph analysis on the radar measurements at Andenes and Kiruna is shown in Fig. 10 for upper tropospheric heights. In both cases, the ellipses have an anticlockwise rotational sense which in the northern hemisphere is related to a downward energy propagation. The ratios of the major to the minor axes of the ellipses, correspond without any wind shear effect to an intrinsic period of $5.2 \mathrm{~h}$ at Andenes and $6.4 \mathrm{~h}$ at Kiruna, respectively. The horizontal propagation of these inertia gravity waves can be derived from the orientation of the ellipses with an uncertainty of $180^{\circ}$ without additional knowledge of temperature or vertical wind perturbations, resulting here to $-12^{\circ}$ at Andenes and $-42^{\circ}$ at Kiruna. This difference may be appear as too large, however, we have to consider that the hodograph is only a snapshot and applicable for monochromatic waves.

In addition, Vincent and Fritts (1987) and Eckermann and Vincent (1989) presented a Stokes-parameter method which results in a set of gravity wave parameters comparable to those of the hodograph analysis, but with the possibility to average over the duration of the wave and selected vertical wave number bands $m \in\left[m_{1}, m_{2}\right]$. We applied here this method on both radar measurements at Andenes and Kiruna during the period with strongest wave activity for vertical wave numbers $m_{1}, m_{2}$ corresponding to wavelengths between $3.8-6.4 \mathrm{~km}$, respectively. Mean results using the Stokes-parameter analysis are presented in Table 2. Note that again the derived parameters as the degree of polarization, $d_{m_{1}, m_{2}}$, the major axis orientation, describing the wave propagation direction $\Theta_{m_{1}, m_{2}}$ for Andenes and Kiruna with values of $-12^{\circ}$ and $-22^{\circ}$, respectively, as well as the ellipse axial ratio $R_{m_{1}, m_{2}}$ are comparable at both locations and to the independent hodograph analyses.

These results are in a sufficient agreement with the hodograph of the wind fluctuations derived from a high-resolution balloon sounding (Fig. 11) launched at Andenes in the frame of the MaC-WAVE campaign. Following Guest et al. (2000) and Peters et al. (2003), the wind fluctuations were 

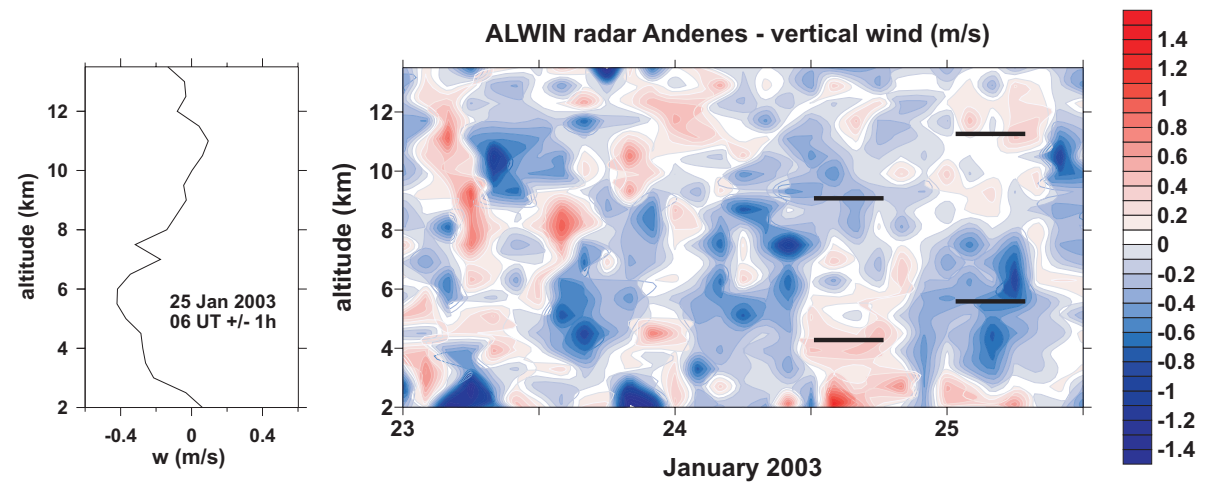

Fig. 7. Vertical winds derived from DBS measurements with the ALWIN VHF radar at Andenes. Left part: Mean profile averaged over $2 \mathrm{~h}$ on 25 January 2003. Right part: Variations of the vertical winds during the period from 23-25 January 2003. The horizontal lines indicate the distance between maxima and minima of the vertical winds.
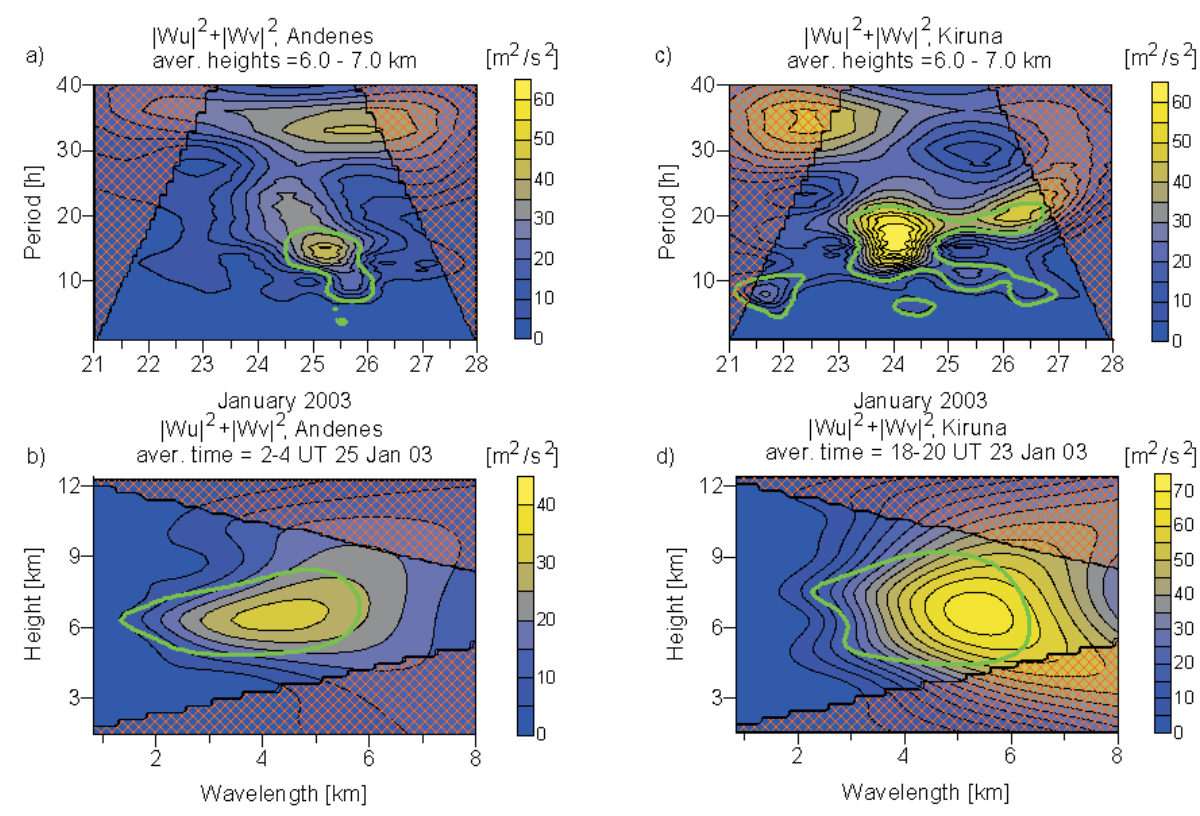

Fig. 8. Sum of the wavelet spectra applied to the zonal and meridional winds. The upper panel (a, c) shows the Morlet wavelet transform of the time series averaged over the altitude ranges $6-7 \mathrm{~km}$. The lower panel (b, d) shows the averaged in time Paul wavelet transforms of vertical profiles of horizontal winds. Wind measurements at Andenes (a, b) and Kiruna (c, d) have been used. Bold green lines indicate regions with $95 \%$ significance level, shaded areas mark zones where boundary effects appear.

determined by the differences between the measured values and a polynomial fit of 4 th order for each component applied on tropospheric heights. From the ratio of the major to the minor axis of the ellipse, we estimate an intrinsic period of $4.2 \mathrm{~h}$. The ellipse with an orientation of about $-83^{\circ}$ shows an anticlockwise rotational sense corresponding to a downward directed energy propagation.

To estimate the intrinsic frequency $\hat{\omega}$ and the horizontal wave number $k_{h}$ of a gravity wave, we use the polarization, dispersion and Doppler equations. The polarization relation is defined as
$R=\left|\frac{f_{c}}{\hat{\omega}}-\frac{k_{h}}{m \hat{\omega}} \frac{\partial \bar{v}}{\partial z}\right|$.

Here the vertical wind shear effect in the background wind, as introduced by Hines (1989), is included by the term $\partial \bar{v} / \partial z$, where $\bar{v}$ denotes the mean horizontal wind component perpendicular to the wave propagation. The dispersion relationship is given by

$\hat{\omega}^{2}=f_{c}^{2}+\frac{N^{2} k_{h}^{2}}{m^{2}}-\frac{2 f k_{h}}{m} \frac{\partial \bar{v}}{\partial z}$. 

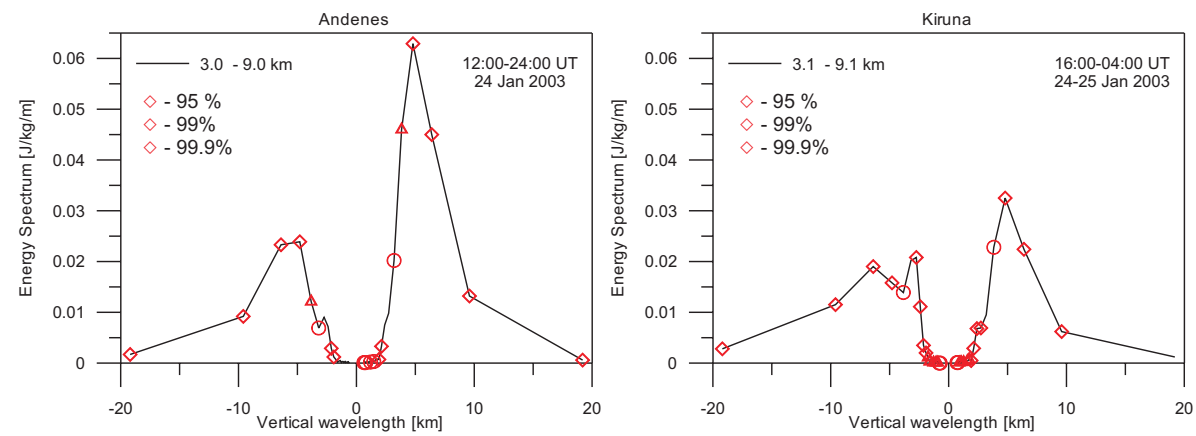

Fig. 9. Results of rotary spectra $(\circ, \triangle, \diamond-$ significance levels) applied to radar wind perturbations after a band-pass filtering with bandwidths of $8-18 \mathrm{~h}$ in time and $2-6 \mathrm{~km}$ in height. The spectra are averaged for $12 \mathrm{~h}$ starting on 24 January 2003, 12:00 UT at Andenes (a) and on 24 January 2003, 16:00 UT at Kiruna (b).
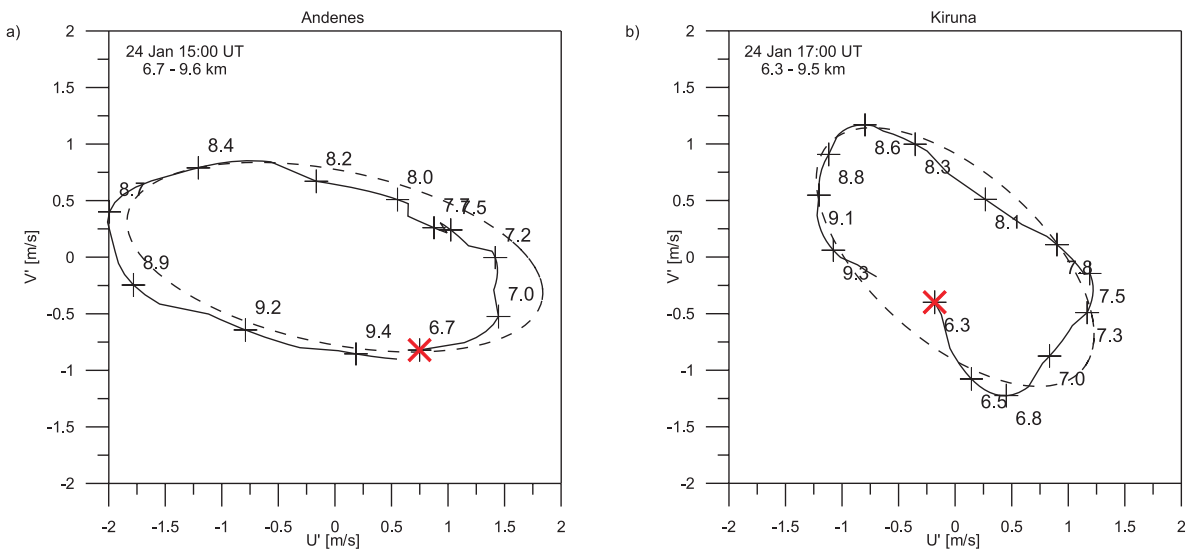

Fig. 10. Results of hodograph analysis (solid line - measured profiles, dashed line - fitted ellipse, $\mathbf{X}$ - starting point of the hodograph) applied to radar measurements at Andenes (a) on 24 January 2003, 15:00 UT and at Kiruna (b) on 24 January 2003, 17:00 UT.

The Doppler relationship is given by Eq. (2). The Coriolis frequency $f_{c}$ depends on the geographical latitude and has been calculated for both radar locations. The Brunt-Väisälä frequency $N(z)$ can be estimated from radiosonde or lidar temperature soundings. In the absence of temperature information in the case of pure radar investigation, the mean Brunt-Väisälä frequency is selected here with a typical value of $0.013 \mathrm{~s}^{-1}$ for the troposphere.

Using the results of the Stokes-parameter analysis applied to the case study presented here (Table 2), the solution of Eqs. (3) and (4) leads to the final gravity parameter given in Table 3, where the Doppler relation (2) is used to solve the sign ambiguity of the horizontal wave number $k_{h}$. Note, that due to the high variability of the background winds during the MaCWAVE winter campaign, a direct evaluation of the Doppler relation between observed and intrinsic frequency is unreasonable. Characteristic parameters like the horizontal wavelengths, the phase and group velocities as well as the orientation of the horizontal propagation show reasonable agreements for the wave events with observed periods of about $13 \mathrm{~h}$, identified and filtered out at both locations before and behind the Scandinavian mountain ridge.
Based on the wavelet transform of the radar measurements at Andenes and Kiruna (Fig. 8a, c) we found a common wave at both locations on 24 January with a period of about $13 \mathrm{~h}$. Note that the high variability of the background winds shows nearly no impact on the obtained wavelet spectra. Furthermore, the direction of the wave propagation at Andenes is nearly the same as at Kiruna (Table 2). It gives us a good ability to apply the cross-spectral analysis as detailed described in Serafimovich et al. (2005). The cross spectrum of the zonal winds measured at Andenes and Kiruna is shown in Fig. 12.

In this case study over Northern Scandinavia we obtained a peak in the cross power spectrum at a period $T_{o b}$ of $\sim 13 \mathrm{~h}$ (Fig. 12a). This peak is significant as shown by the coherency spectrum (Fig. 12b). Thus we conclude, that the presented results for both locations are linked to the same wave.

\section{Discussion}

In the frame of the MaCWAVE winter campaign in January 2003 we show that collocated VHF radar measurements can 
Table 3. Gravity waves parameters derived from the results of the Stokes-parameter analysis as shown in Table 2 for the radar measurements at Andenes and Kiruna.

\begin{tabular}{lcc}
\hline IGW parameters & Andenes & Kiruna \\
\hline Intrinsic period, $2 \pi / \hat{\omega}, \mathrm{h}$ & 5.6 & 4.3 \\
Observed period, $2 \pi / \omega_{o b}, \mathrm{~h}$ & 12.8 & 12.8 \\
Vertical wavenumber, $m, \mathrm{~m}^{-1}$ & $1.37 \times 10^{-3}$ & $1.31 \times 10^{-3}$ \\
Vertical wavelength, $2 \pi /|m|, \mathrm{km}$ & 4.6 & 4.8 \\
Horizontal wavenumber, $k_{h}, \mathrm{~m}^{-1}$ & $-2.72 \times 10^{-5}$ & $-3.61 \times 10^{-5}$ \\
Horizontal wavelength, $2 \pi /\left|k_{h}\right|, \mathrm{km}$ & 231 & 174 \\
Horizontal phase velocity, $v_{p h}, \mathrm{~ms}^{-1}$ & -11.5 & -11.2 \\
Vertical phase velocity, $v_{p z}, \mathrm{~ms}^{-1}$ & 0.23 & 0.31 \\
Horizontal group velocity, $c_{g h}, \mathrm{~ms}^{-1}$ & -8.8 & -9.6 \\
Vertical group velocity, $c_{g z}, \mathrm{~ms}^{-1}$ & -0.175 & -0.265 \\
Wind shear component, $\partial \bar{v} / \partial z, \mathrm{~s}^{-1}$ & $1.7 \times 10^{-3}$ & $1.2 \times 10^{-3}$ \\
\hline
\end{tabular}

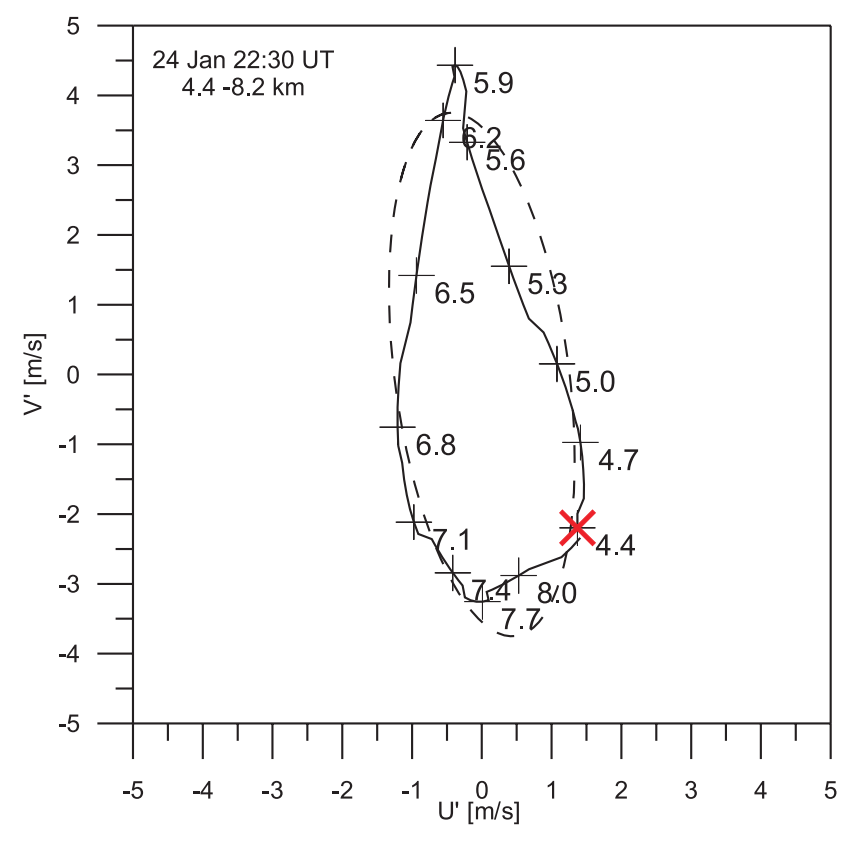

Fig. 11. Hodograph of tropospheric wind fluctuations derived from high-resolution balloon sounding launched near Andenes at $\sim 22: 30$ UT on 24 January 2003 at Andenes. The data are averaged over $300 \mathrm{~m}$. The dashed line shows the fitted ellipse, the red cross marks the starting point.

be used to identify and to investigate inertia gravity waves in the troposphere/lower stratosphere. During the first part of the campaign, we detected an enhanced activity of different gravity waves with observed periods larger than $8 \mathrm{~h}$ (Figs. 4 and 5) in connection with an eastward directed jet stream towards the Scandinavian mountains (Fig. 1).

The evaluation of the rotary spectra (Figs. 6 and 9) results in the detection of an inertia gravity wave packet with down- ward directed energy propagation having a vertical wavelength of $\sim 5 \mathrm{~km}$. Furthermore, a mountain wave with an upward directed energy propagation was found which shows a vertical wavelength of $\sim 10 \mathrm{~km}$ at Andenes, but larger amplitudes with a shorter vertical wavelength $(\sim 7 \mathrm{~km})$ on the lee side of the Scandinavian mountain ridge at Kiruna. Possible explanations for these observed shorter vertical wavelengths at Kiruna could be related to differences of the background winds at both locations and to stronger lee waves at Kiruna leading to changed superpositions of all waves. However, such studies remain a topic for future mesoscale model simulations. Additionally, the height-time plot of the vertical winds at Andenes (Fig. 7) indicates transient mountain waves as shown by the phase changes during periods with changing horizontal winds (Fig. 3). Such an evolution due to a varying mean flow towards the mountains has been discussed by Vosper and Worthington (2002) in more details. However, the influence of the mountain waves on the inertia gravity waves as well as possible interactions remain a topic of a future study.

Focussing on the inertia gravity waves with shorter vertical wavelengths, a wavelet transform has been applied to separate these waves from the mountain waves and to investigate the height and time dependencies of the inertia gravity waves at both radar locations. Figure 8 shows dominant vertical wavelengths of about $4-5 \mathrm{~km}$ and dominant observed periods of about $13-14 \mathrm{~h}$ in the altitude range between 5 and $8 \mathrm{~km}$ with higher amplitudes on the lee side of the Scandinavian mountain ridge at Kiruna, probably caused by an amplification due to the mountain waves. From the identified downward energy propagation (Figs. 9, 10, and 11) we found that the waves are likely generated by the jet streak in the upper troposphere. This assumption is supported by investigations of Zülicke and Peters (2006) using model simulations of inertia gravity waves mainly generated through 

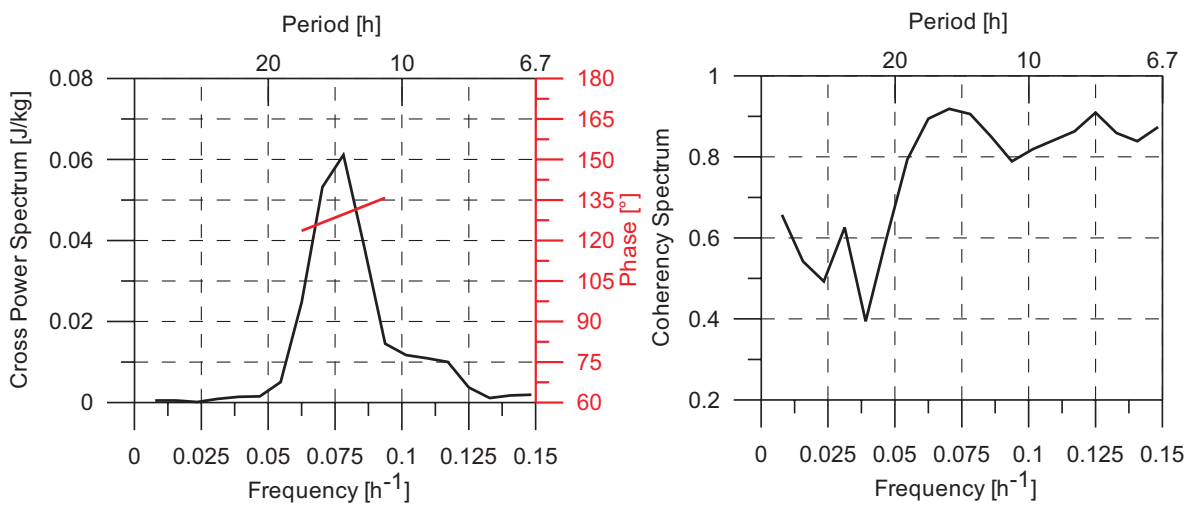

Fig. 12. Cross-power spectrum between radar measurements at Andenes and Kiruna for the time from 24 January 2003, 00:00 UT to 26 January 2003, 24:00 UT, averaged over the height range from $4 \mathrm{~km}$ to $8 \mathrm{~km}$. Left part: Amplitude (black) and phase difference (red). Right part: Coherency spectra.

spontaneous radiation in the exit region of the upper tropospheric jet.

The parameter of these inertia gravity waves were estimated by the Stokes analysis of the radar measurements at Andenes and Kiruna separately (Table 3), and are in a qualitatively good agreement, what we expect if the radars detect the same wave packet. The results show the appearance of coherent dominating inertia gravity waves with vertical wavelengths of $\sim 5 \mathrm{~km}$ and intrinsic periods in the order of $\sim 5 \mathrm{~h}$. These waves with characteristic horizontal wavelengths of $200 \mathrm{~km}$ are moving in the opposite direction than the mean background wind.

Furthermore, the data during the first part of the winter MaCWAVE campaign have been used in a companion paper (Part II, Serafimovich et al., 2006) for estimations of the gravity wave induced vertical fluxes of horizontal momentum and for comparisons between observations and mesoscale MM5 model simulations of inertia gravity waves.

During the second part of the campaign on 28-29 January 2003 nearly no wave activity has been observed in the upper troposphere at Andenes (Fig. 4) and Kiruna (Fig. 5) as expected by the weaker stream directed more parallel to the Scandinavian mountains.

\section{Conclusion}

We presented here an experimental study of inertia gravity waves in the upper troposphere near the Scandinavian mountain Ridge in the frame of the MaCWAVE winter campaign. Using continuous radar measurements with the ALWIN radar at Andenes and the ESRAD radar near Kiruna, we found, that the strongest gravity wave activity in the troposphere occurred during the first part of the winter MaCWAVE campaign on 24-26 January, whereas during the second part of the campaign on 28-29 January 2003 nearly no wave activity has been observed.
Gravity wave parameters estimated by the analysis of radar measurements at Andenes and Kiruna separately are in qualitatively good agreement. During the first period, wavelet transformations reflect similar wave structures in the upper troposphere at both locations. Under the influence of a transient mountain wave, the results show the appearance of coherent dominating inertia gravity waves moving in the opposite direction than the mean background wind. Both methods, the rotary spectra and the hodograph technique, yield to downward energy propagations, so that the identified gravity wave packet is likely generated by the jet streak in the upper troposphere. On the east-side of the Scandinavian mountain ridge the inertia gravity waves show higher amplitudes as an indication of the influence of mountain waves.

In a companion paper (Part II, Serafimovich et al., 2006), gravity wave induced vertical fluxes of horizontal momentum are estimated and comparisons are presented between observations and mesoscale MM5 model results. The model data agree with the experimentally obtained results fairly well and the capabilities of both methods, the VHF radar observations with their high temporal and vertical resolutions and the model analyses to get more insight in the atmospheric processes, have been proved.

Further analyses of unsteady mountain waves generated in that region and investigations of their interactions with the identified jet induced inertia gravity waves are necessary. Combined model analysis in connection with observations will contribute to understand such processes.

Acknowledgements. The authors thank their colleagues for the support to operate the VHF radars, additionally supported by an "Access to the ALOMAR research infrastructure" project CT-2003506208 of the European Community. The data supply from ECMWF via the German Meteorological Service "Deutscher Wetterdienst" (DWD) is acknowledged.

Topical Editor U.-P. Hoppe thanks P. Chilson and another referee for their help in evaluating this paper. 


\section{References}

Balsley, B. B. and Carter, D. A.: Mountain waves in the tropical pacific atmosphere - a comparison of vertical wind fluctuations over Pohnpei and Christmas Island using VHF wind profilers, J. Atmos. Sci., 46, 2698-2715, 1989.

Chilson, P. C., Kirkwood, S., and Nilsson, A.: The Esrange MST radar: A brief introduction and procedure for range validation using balloons, Radio Sci., 34, 427-436, 1999.

Cot, C. and Barat, J.: Wave-turbulence interaction in the stratosphere: A case study, J. Geophys. Res., 91, 2749-2756, 1986.

Eckermann, S. and Vincent, R.: Falling sphere observations gravity waves motions in the upper stratosphere over Australia, Pure Appl. Geophys., 130, 509-532, 1989.

Ecklund, W. L., Gage, K. S., and Riddle, A. C.: Gravity wave activity in vertical winds observed by the Poker Flat MST radar, Geophys. Res. Lett., 8, 285-288, 1981.

Fritts, D. C.: Gravity wave saturation in the middle atmosphere: A review of theory and observations, Rev. Geophys. Space Phys., 22, 275-308, 1984.

Fritts, D. C.: A review of gravity wave saturation processes, effects, and variability in the middle atmosphere, Pure Appl. Geophys., 130, 343-317, 1989.

Fritts, D. C. and Alexander, M. J.: Gravity wave dynamics and effects in the middle atmosphere, Rev. Geophys., 41(1), 1003, doi:10.1029/2001RG000106, 2003.

Gill, A. E.: Atmosphere-Ocean Dynamics, Academic Press, New York, 1982.

Goldberg, R., Fritts, D., Williams, B., Lübken, F.-J., Rapp, M., Singer, W., Latteck, R., Hoffmann, P., Müllemann, A., Baumgarten, G., Schmidlin, F., She, C.-Y., and Krueger, D.: The MaCWAVE/MIDAS rocket and ground-based measurements of polar summer dynamics: Overview and mean state structure, Geophys. Res. Lett., 31, L24S02, doi:10.1029/2004GL019411, 2004.

Goldberg, R., Fritts, D., Schmidlin, F., Williams, B., Croskey, C., Mitchell, J., Friedrich III, M., J. R., Blum, U., and Fricke, K.: The MaCWAVE program to study gravity wave influences on the polar mesosphere, Ann. Geophys., 24, 1159-1173, 2006, http://www.ann-geophys.net/24/1159/2006/.

Guest, F. M., Reeder, M. J., Marks, C. J., and Karoly, D. J.: Inertiagravity waves observed in the lower stratosphere over Macquarie Island, J. Atmos. Sci., 57, 737-752, 2000.

Hines, C. O.: Internal atmospheric gravity waves at ionospheric heights, Can. J. Phys., 38, 1441-1481, 1960.
Hines, C. O.: Tropopausal mountain waves over Arecibo: A case study, J. Atmos. Sci., 46, 476-488, 1989.

Latteck, R., Singer, W., and Bardey, H.: The Alwin MST radar technical design and performance, in: Proceedings of the 14th ESA Symposium on European Rocket and Balloon Programmes and Related Research, Potsdam, Germany (ESA SP-437), edited by: Kaldeich-Schürmann, B., pp. 179-184, ESA Publications Division, 1999.

Peters, D., Hoffmann, P., and Alpers, M.: On the appearance of inertia gravity waves on the north-easterly side of an anticyclone, Meteor. Z., 12, 25-35, 2003.

Queney, P.: The problem of air flow over mountains: A summary of theoretical studies, Bull. Amer. Meteor. Soc., 29, 16-26, 1948.

Schöch, A., Baumgarten, G., Fritts, D. C., Hoffmann, P., Serafimovich, A., Wang, L., Dalin, P., Müllemann, A., and Schmidlin, F. J.: Gravity waves in the troposphere and stratosphere during the MaC/MIDAS summer rocket program, Geophys. Res. Lett., 31, L24S04, doi:10.1029/2004GL019837, 2004.

Serafimovich, A., Hoffmann, P., Peters, D., and Lehmann, V.: Investigation of inertia-gravity waves in the upper troposphere / lower stratosphere over Northern Germany observed with collocated VHF/UHF radars, Atmos. Chem. Phys., 5, 295-310, 2005, http://www.atmos-chem-phys.net/5/295/2005/.

Serafimovich, A., Zülicke, C., Hoffmann, P., Peters, D., Dalin, P., and Singer, W.: Inertia Gravity waves in the upper troposphere during the MaCWAVE winter campaign, Part II: Radar investigations and modelling studies, Ann. Geophys., 24, 2863-2875, 2006, http://www.ann-geophys.net/24/2863/2006/.

Smith, R. B.: The influence of mountains on the atmosphere, Adv. Geophys., 21, 87-230, 1979.

Thompson, R. O. R. Y.: Observation of inertial waves in the stratosphere, Quart. J. Roy. Meteorol. Soc., 104, 691-698, 1978.

Torrence, C. and Compo, G. P.: A practical guide to wavelet analysis, Bull. Amer. Meteor. Soc., 79, 61-78, 1998.

Vincent, R. A. and Fritts, D. C.: A climatology of gravity wave motions in the mesopause region at Adelaide, Australia, J. Atmos. Sci., 44, 748-760, 1987.

Vosper, S. B. and Worthington, R. M.: VHF radar measurements and model simulations of mountain waves over Wales, Quart. J. Roy. Meteorol. Soc., 128, 185-204, 2002.

Zink, F. and Vincent, R.: Wavelet analysis of stratospheric gravity wave packets over Macquarie Island, J. Geophys. Res., 106, 10 275-10 288, 2001.

Zülicke, C. and Peters, D.: Inertia-gravity waves driven by a poleward breaking Rossby wave, J. Atmos. Sci., in press, 2006. 